Infect Dis Clin North Am. 2008 September ; 22(3): 449-viii. doi:10.1016/j.idc.2008.03.006.

\title{
Tick-Borne Relapsing Fever
}

Mark S. Dworkin, MD, MPH TMa, ${ }^{\star}$, Tom G. Schwan, $\mathrm{PhD}^{\mathrm{b}}$, Donald E. Anderson Jr, $\mathrm{PhD}^{\mathrm{c}}$, and Stephanie M. Borchardt, PhD, MPH ${ }^{d}$

aDivision of Epidemiology and Biostatistics, University of Illinois at Chicago, School of Public Health, 1603 West Taylor Street, Chicago, IL 60612, USA

bLaboratory of Human Bacterial Pathogenesis, Rocky Mountain Laboratories, National Institutes of Allergy and Infectious Diseases, National Institutes of Health, 903 South Fourth Street, Hamilton, MT 59840, USA

'College of Pharmacy, Washington State University, 2015 East 55th, Spokane, WA 99223, USA

dFargo Veterans Administration Medical Center, 2101 Elm Street N, Fargo, ND 58102, USA

Relapsing fever is characterized by recurring episodes of fever and nonspecific symptoms (eg, headache, myalgia, arthralgia, shaking chills, and abdominal complaints). The illness is caused by infection with Borrelia species that vary their surface antigens, lending to repeated spirochetemias and stimulation of the immune system by each new antigen and a febrile response by the patient [1,2]. These Borrelia (spirochetes) are transmitted to humans by exposure to the bite of an infected Ornithodoros tick (TBRF) or contact with the hemolymph of an infected human body louse (Pediculus humanus) (louse-borne relapsing fever [LBRF], or epidemic relapsing fever) [3]. LBRF is caused by infection with Borrelia recurrentis. These spirochetes are introduced by crushing the louse (eg, when scratching), which releases the insect's infected hemolymph and contaminates abraded or normal skin and mucous membranes. LBRF occasionally is imported into the United States in a traveler [4]. The last outbreak in the United States was probably in New York in 1871 [5]. Unless specified as $T B R F$, in this article the term relapsing fever refers to information known about TBRF and LBRF.

In the United States, the first report of TBRF occurred in 1905 in New York in a traveler to Texas [6]. TBRF has been recognized in the western United States since it was reported in Jefferson County, Colorado, in 1915 [7]. Because this early report of five cases included four campers having had recent contact with a band of European Gypsies, it was not until 1939, when $O$ hermsi was discovered in this region of Colorado, that TBRF was established as endemic there [8]. Early reports of TBRF should be distinguished from the earliest report of relapsing fever in the United States, an outbreak of LBRF in Philadelphia in 1844 among immigrants from Liverpool [5].

Many states reported cases of TBRF during the first half of the twentieth century, including California (1922); Montana, Texas, and Washington (1927); Arizona and Nevada (1930); Idaho and Kansas (1931); New Mexico (1936); Utah (1939); and Oregon and Oklahoma (1940) $[3,5,9-12]$.

(C) 2008 Elsevier Inc. All rights reserved.

"Corresponding author. mdworkin@uic.edu (M.S. Dworkin). 


\section{Epidemiology}

TBRF is found throughout most of the world. It is endemic in the western United States, southern British Columbia, the plateau regions of Mexico, Central and South America, the Mediterranean, Central Asia, and throughout much of Africa [1]. In the United States, TBRF exposure sites typically are in limestone caves in central Texas and in forested areas at varying elevations in mountainous regions (Cascade, Rocky Mountain, San Bernardino, and Sierra Nevada ranges) of the United States. Only 13 counties have accounted for approximately 50\% of all cases (Fig. 1). In the Northwest, the greatest number of cases was reported from northeastern Washington State and northern Idaho, where passive and active surveillance activities began during the 1990s [13]. In Utah, the area east of Salt Lake City is noteworthy for TBRF reports. Many cases of TBRF in United States were associated with travel to Lake Coeur D' Alene and Hayden Lake (Idaho), Packer Lake, Big Bear Lake, and Lake Tahoe (California and Nevada), and several outbreaks have been described in Spokane County, Washington; Estes Park, Colorado; the North Rim of the Grand Canyon; San Bernardino County, California; Crockett and Starr Counties, Texas; Lake County, Montana; and northern New Mexico (Table 1) [14-22]. Infected ticks have been found in regions where TBRF cases have not been confirmed [13,23]. In Canada, British Columbia is the only province with endemic TBRF [13]. Early reports implicated the West Kootenay region (Arrow Lake), and more recent reports showed exposure in the Okanagan Valley in southern British Columbia [24,25]. Surveillance of TBRF likely reflects substantial underreporting and, therefore, the precise distribution of disease is not optimally characterized.

TBRF in the United States typically is not reported farther east than Montana, Colorado, New Mexico, and Texas. Historically, cases have been acquired in Oklahoma, Kansas, and Ohio [26-28]. A report showed a species of Borrelia spirochetes in the northeastern United States previously unknown in North America and transmitted by Ixodes scapularis [29]. This spirochete was genetically similar to Borrelia miyamotoi, which is known to have genetic similarities to the relapsing fever borreliae. This discovery has not been associated yet with human disease, however. A case of relapsing fever has been reported in a park ranger with exposure most likely in the United States Virgin Islands (but with travel to Maryland and Maine approximately 2 to 3 months before illness onset) [30]. A case of TBRF was acquired in Wyoming (the first in that state) [24].

\section{Etiologic agent}

The borreliae are helical organisms that are actively motile. Their size ranges from 3 to 25 $\mathrm{mm}$ long and 0.2 to $0.5 \mathrm{~mm}$ wide. In fixed, Wright-stained differential smears, they appear as loose coils [31]. Borrelia have the ability to generate repetitive cycles of disease through a process known as antigenic variation [32], which is manifested by the sequential appearance of new outer surface proteins during the course of the disease [33]. Two Borrelia species associated with a relatively high fatality rate from relapsing fever are $B$ recurrentis and Borrelia duttoni [34]. B duttoni is transmitted by the soft tick, Ornithodoros moubata, and is found in East Africa, whereas $B$ recurrentis is found in many parts of the world, especially Africa but including South America, Europe, and Asia. Humans are the only known vertebrate host of these two species. There are many other Borrelia species. In North America, the two principal agents of TBRF are Borrelia hermsii and Borrelia turicatae [31]. Borrelia dugesi and $B$ turicatae have been reported in Mexico [3,35].

Soft ticks of the family Argasidae (Ornithodoros species) transmit most members of relapsing fever borreliae except $B$ recurrentis. Typically, the Borrelia species take their specific names from the soft ticks (Ornithodoros species) that transmit them. In North America, $O$ hermsi transmits $B$ hermsii, $O$ turicata transmits $B$ turicatae, and $O$ parkeri 
transmits Borrelia parkeri [31]. Borreliae also have been transmitted by blood transfusion, intravenous drug use, and laboratory worker accidents, including the bite from an infected monkey that was bleeding from its gums [36-39].

\section{Vector biology and ecology}

TBRF occurs where the appropriate species of Ornithodoros ticks and mammals maintain spirochetes in enzootic cycles. Similar to all zoonoses, people succumb to relapsing fever when they live in or enter temporarily these endemic regions and are infected when fed on by infectious ticks. In North America, essentially all single human cases or outbreaks of TBRF are associated with two species of ticks found in restricted foci west of the Mississippi River. These ticks, $O$ hermsi and $O$ turicata, have a similar life cycle but have different habitats and hosts.

Both species of Ornithodoros ticks have similar gross morphologies (Fig. 2) and life cycles that include egg, single larva, and several successive nymphs before becoming either an adult male or female. All stages are obligate blood feeders and are capable of transmitting spirochetes when they feed. These ticks feed quickly within 15 to 90 minutes, with the larvae and smaller nymphs usually feeding in less time than the larger nymphs and adults. The larvae and younger nymphs usually molt to the next stage after one blood meal, whereas the larger nymphs may feed twice before molting. As adults, Ornithodoros ticks feed repeatedly and can live for many years in protected environments that offer favorable temperature and relative humidity. The females lay clutches of eggs after each blood meal. This reproductive pattern is strikingly different than that of hard ticks, which as adult females feed and reproduce only once and die.

O hermsi is distributed in southern British Columbia,Washington, Idaho, Oregon, California, Nevada, northern Arizona, northwestern New Mexico, Utah, Montana, and Colorado $[14,15,21,22,40,41]$. O hermsi lives in coniferous forests at elevations of 1500 to 8000 feet and feeds primarily on ground squirrels, tree squirrels, and chipmunks, which often are plentiful near fresh water lakes that attract tourists [13]. The ticks live in close association with these diurnal rodents, infesting their nest or cracks and cavities in trees or structures near the rodent's nest. Also, infected ticks, transported by their shelter-seeking vertebrate hosts, may be found in seldom-occupied, rustic cabins and sometimes in permanently occupied residences [13,42].

Ticks feed at night when their natural hosts are resting in the nest. Vertical transmission of spirochetes from an infected female to her offspring (transovarial transmission) is rare so that larvae are unlikely to be infectious when they feed. Spirochetes are passed through the molt from one stage of the life cycle to the next (transstadial transmission). Many tick tissues are susceptible to spirochete infection, but a persistent infection of the salivary glands [43] allows these ticks to transmit spirochetes quickly during their short feeding period, possibly after only 30 seconds of attachment [41].

The usual ecologic setting for humans to become infected with $B$ hermsii is a seasonally occupied lake or mountain cabin that is or has been infested with rodents and their ticks. If rodents no longer infest a dwelling but ticks are present, humans become the only available host. At night, ticks become active, wander and search for hosts, orienting to the carbon dioxide released in their breath. Ticks enter beds, cots, or sleeping bags and feed rapidly, then return to the place from which they came. The victims rarely are aware of having been bitten by these ticks. Sometimes the ticks are unable to leave the bedding and may be found in blankets the following morning. Researchers sleeping on a tick-infested wooden platform on an island in Mono Lake, California, frequently were bitten by these ticks, which were found each morning in the sleeping bags [44]. 
O turicata occurs from Kansas south to central Mexico, west to California, with a disjunct population in Florida, where no human cases have been reported [5,40]. Collection records for this species include California, Utah, Colorado, New Mexico, Arizona, Oklahoma, Kansas, Florida, and Texas [40]. The tick prefers drier habitats at lower elevations, and many collections are from underground burrows with the hosts undetermined. In Texas, $O$ turicata often is found in caves [19]. The ticks have been collected in association with numerous animals, including cattle, pigs, ground squirrels, prairie dogs, gopher tortoises, and snakes [40]. In the laboratory, $O$ turicata feed well on mice, but it is unclear how important rodents are as hosts for these ticks in the wild. Infection of $B$ turicata in dogs in Texas [19] suggests that coyotes also may be natural hosts for this tick. Most human cases of $B$ turicatae have been identified from exposure in Texas; older data document cases in Kansas and Oklahoma [27,31].

O turicata is significantly larger than $O$ hermsi, has an integument with conspicuous conical mammillae, and has dorsal projections on the distal segment (tarsus) of the front legs (see Fig. 2). This tick is the vector of $B$ turicatae and all stages of the tick transmit spirochetes by bite. Transovarial transmission of $B$ turicatae in $O$ turicata occurs much more frequently than does $B$ hermsii in $O$ hermsi. This tick also excretes large amounts of coxal fluid during or shortly after feeding, whereas $O$ hermsi does not. $O$ turicata may transmit spirochetes in coxal fluid and by bite. Similar to most species of soft ticks, this tick can fast for long periods. Infected $O$ turicata have transmitted spirochetes in the laboratory after 7 years without a blood meal [45]. The disjunct population of this tick in Florida is considered a subspecies and is designated $O$ turicata americanus [46]. No human cases of TBRF have been reported in Florida, although $B$ turicatae has been isolated there from a dog [47]. More attention needs to be directed at possible TBRF in humans in Florida because of the presence of $O$ turicata and $B$ turicatae there [48].

$O$ parkeri occurs throughout much of the western United States and is the vector of another species of relapsing fever spirochete, $B$ parkeri. $O$ parkeri is found in burrows, rodent nests, and caves in arid regions, grasslands, or treeless grassy plains [14,49]. Only one human case of TBRF has been reported after the bite of $O$ parkeri, [41] and the public health significance of this tick and spirochete is uncertain.

\section{Pathogenesis}

The phenomenon of antigenic variation contributes to the recurring nature of relapsing fever [33]. The outer membrane of relapsing fever spirochetes contains surface proteins that have been termed variable small proteins (Vsp) and variable large proteins (Vlp) (formerly called variable major proteins) [50]. The characteristic disease pattern of recurrent febrile episodes interspersed with asymptomatic episodes is associated with changes in these proteins that are encoded within the DNA of linear plasmids [33]. The serotype-specific surface proteins are expressed sequentially one at a time and present an ensemble of proteins to which the host has a sequential immunologic response. Organisms evade eradication by modification of the immunogenic outer surface antigens, facilitating renewed febrile episodes.

High-level spirochetemia is a characteristic of relapsing fever. Typically, an average of five organisms per oil immersion field are observed in routine differential, fixed blood smears of patients during the acute febrile phase of illness [13]. During symptomatic disease, estimates of bacterial blood concentrations in humans and experimental animals range from $10^{5}$ to greater than $10^{6}$ spirochetes per milliliter of blood [32,51]. During asymptomatic intervals, the organisms are microscopically undetectable in the bloodstream. In the laboratory of one of the authors (DEA), wet mounts of blood were examined from two patients who had been afebrile for 6 to 8 hours after experiencing their first relapse. TBRF was suspected because 
immediately before their initial febrile onset, history revealed the patients' exposure at a known, multicase residence. Blood examination revealed rare, motile spirochetes by darkfield microscopy. Later examination of fixed smears showed an average of one spirochete per 320 oil immersion fields, an organism concentration essentially undetectable by conventional microscopy. Based primarily on experimental animal data, the organisms during the asymptomatic intervals are sequestered in internal organs, such as liver, spleen, bone marrow, or the central nervous system [31].

Most information on the pathophysiologic aspects of fatal cases comes from autopsy data of louse-borne disease in humans or experimental animals. Complications include involvement of liver, spleen, lung, heart, gastrointestinal tract, eyes, and central nervous system. Generalized, nonspecific dermatologic manifestations also have been reported [3]. In a report of infections acquired in regions endemic for $B$ hermsii, possible renal involvement was described, but no evidence of central nervous system infection was found among cases of central nervous system manifestations [13]. Urologic involvement may include dysuria, proteinuria, and microhematuria. The large numbers of circulating spirochetes seen in this disease possibly could cause renal glomerular or tubulointerstitial disease. Spirochetes have been described in the urine during acute illness with TBRF [13,28]. Moderate-to-severe thrombocytopenia, although not associated with mortality, is a typical finding in acute TBRF. Bleeding complications, such as epistaxis, purpura, hemoptysis, hematemesis, bloody diarrhea, hematuria, subarachnoid and cerebral hemorrhages, splenic rupture, and retinal hemorrhage are more common with LBRF [1].

Mortality from TBRF in North America is rare and has been associated with complications during pregnancy, including spontaneous abortion, premature birth, or neonatal death [1]. Transmission may be either in utero (transplacental) or during birth [52,53]. Transplacental transmission has resulted in splenic abscesses, meningitis, and death in a neonate [52].

In a more recent case of neonatal infection, a full-term infant was born to a mother who had undiagnosed relapsing fever in the early third trimester of pregnancy. She had a single relapse and recovered without therapy. The pregnancy appeared to proceed without complications until fetal distress was noted at near term. At birth by cesarean section, the placental and neonatal blood was estimated to have spirochetal concentrations of greater than $10^{6}$ organisms per $1 \mathrm{~g}$ of tissue and blood. Shortly after birth, ultrasound examination showed hepatic involvement. The infant died after 10 days of apparently appropriate antimicrobial therapy (ie, no organisms were found in any postmortem specimens). Greater than $300 \mathrm{~mL}$ of blood was found in the abdominal cavity. Death was attributed to hemorrhage within a hepatic abscess that apparently dissected the surface of the liver, forming a subcapsular hematoma that eventually ruptured [54].

\section{Clinical manifestations}

The mean incubation period of TBRF is 7 days (range, 4 to $>18$ days) [3]. The clinical manifestations of TBRF and LBRF are similar, although not identical in their signs and symptoms. The frequency of the clinical manifestations have been described in a relatively large case series of TBRF acquired in the northwestern United States and southwestern Canada (Table 2) [13]. Alteration of sensorium, abdominal pain, and vomiting are common. Diarrhea may occur in $25 \%$ of cases [13]. Persons with LBRF are more likely to have jaundice; central nervous system involvement; petechiae on the trunk, extremities, and mucous membranes; epistaxis; and blood-tinged sputum [1]. Uncommon manifestations of relapsing fever include iritis, acute respiratory distress syndrome, uveitis, iridocyclitis, cranial nerve palsy and other focal neurologic deficits, myocarditis, and rupture of the spleen. Acute respiratory distress syndrome may occur more frequently in patients with 
TBRF than previously recognized and can occur in patients without predisposing conditions [55]. A recent review of case-report forms for all TBRF cases reported to Nevada and California state and local health departments from 1995 to 2004 found two cases of acute respiratory distress syndrome (ARDS). A similar review conducted in Washington state from 1996 to 2005 found three cases of ARDS. All five cases of TBRF-associated ARDS occurred after 2001 [55]. Before 2001, only one case of TBRF with ARDS had been described. The average length of the first episode of TBRF is 3 days (range, 12 hours to 17 days), and it terminates with a crisis [1]. In contrast, the average length for LBRF is 5.5 days (range, 4 to 10 days). The average time between the first episode and the first relapse is 7 days for TBRF and 9 days for LBRF. The patient may have symptoms such as malaise during afebrile intervals or may feel well.

Individual variability between relapsing fever cases is common. Therefore, a careful history of present illness, physical examination, and consideration of relapsing fever in the differential diagnosis are important to avoid misdiagnosis. Failure to diagnose promptly can lead to prolonged (untreated) illness and be expensive because of additional (preventable) medical costs. One patient may present as having meningitis, another may appear flulike, whereas others may have a febrile gastrointestinal illness or no physical findings, and all could receive a variety of invasive and noninvasive testing.

Generally, death occurs more frequently in untreated LBRF than with TBRF. A patient's nutritional status may play a significant role in the outcome, however. LBRF often occurs in the setting of famine or overcrowding where nutrition may be poor, and additional diseases may complicate the diagnosis or disease course. The fatality rate for LBRF is $5 \%$ in treated persons and much lower for TBRF [1].

The differential diagnosis of infectious diseases causing fevers that may relapse or have biphasic patterns includes Colorado tick fever, yellow fever, dengue fever, African hemorrhagic fevers (eg, Lassa fever), lymphocytic choriomeningitis, brucellosis, malaria, leptospirosis, chronic meningococcemia, rat bite fever, ascending (intermittent) cholangitis, and infection with echovirus 9 and Bartonella species. A history of travel, place of residence, and animal exposures is useful in patients who have these fever patterns.

\section{Laboratory diagnosis}

\section{Detection and isolation of spirochetes}

Laboratory confirmation of TBRF is made by the detection or isolation of spirochetes from the patient's blood during a febrile episode [56]. A thin smear or thick drop of blood is applied to a standard glass microscope slide and stained with Wright or Giemsa stain and examined with a bright-field microscope at $1000 \times$ with oil immersion. Spirochetes also may be visualized by direct or indirect immunofluorescent staining and examination with a fluorescence microscope. A wet mount of the blood may be examined with a bright-field microscope to detect erythrocytes moving erratically as a result of spirochetes bumping them in the suspension. A dark-field microscope may be used to observe spirochetes in the blood. Microscopic observation of spirochetes is relatively insensitive because a density of at least $10^{4}$ to $10^{5}$ spirochetes per $1 \mathrm{~mL}$ of blood is needed for the bacteria to be seen. Spirochetes in infected patients may be missed by microscopy. Four factors that may contribute to poor detection on a peripheral smear are the microscopist's inexperience, lack of suspicion for relapsing fever, increased use of automated differentials, and examination of blood in the asymptomatic interval when spirochetes are absent from the circulation or are below the level of detection. Quantitative buffy coat analysis is an alternative method that appears to be 100 times more sensitive in vitro than thick film examination; however, special equipment is required [57,58]. 
Patient's blood may be inoculated into mice to amplify the number of spirochetes to a detectable level in the animal's blood. This technique is rarely if ever used today in the diagnostic laboratory but is still useful in the research setting. Spirochetes also may be cultivated in vitro with a specific medium developed by Kelly [59]. A few drops of a patient's blood are inoculated into this liquid broth, incubated at $30^{\circ} \mathrm{C}$ to $37^{\circ} \mathrm{C}$, and examined with a dark-field microscope for 2 to 6 weeks postinoculation for the presence of spirochetes.

In the past, spirochetes causing TBRF were not identified to the species level. The identity was assumed, based on the patient's place of exposure and the tick most likely to have transmitted the infection. If the patient slept in a lake or mountain cabin, the probable tick was $O$ hermsi, and the spirochete causing the infection was assumed to be $B$ hermsii. If the patient camped in a Texas cave, the probable tick was $O$ turicata, and the infecting organism was likely to be $B$ turicatae. Regardless of the species of spirochete infecting the patient, the treatment is the same. Many of the techniques available today did not exist years ago to identify bacteria rapidly, especially those that could not be grown in vitro. Today, $B$ hermsii is identifiable with a specific monoclonal antibody [60]. Most species of Borrelia can be identified by polymerase chain reaction amplification and analysis of speciesspecific markers in genomic DNA [61].

Epidemiologic investigations of outbreaks of TBRF use the same techniques to examine the blood of wild animals for spirochetes as are used for human blood samples. Rodents are trapped alive, and their blood is examined for spirochetes in stained smears, or attempts to isolate organisms can be performed in laboratory mice or liquid medium. Ornithodoros ticks found at the patient's place of exposure can be examined for spirochetes with one of several methods. Ticks can be triturated and inoculated into medium or laboratory mice. Live ticks can be fed on laboratory mice for transmission of spirochetes. Tick tissues can be dissected and smeared on a microscope slide and stained with Giemsa or immunofluorescent-labeled antibodies for the microscopic detection of spirochetes.

\section{Serology}

Serologic confirmation of TBRF is demonstrated with a fourfold rise in antibody titer between the acute and convalescent serum samples or with a single convalescent serum sample that is diagnostically reactive. Relatively few diagnostic laboratories are able to perform serologic testing for TBRF, however, and where this is done, improvements in the specificity of the tests are needed. The ability to cultivate these bacteria and produce large amounts of test antigen has allowed the development of a variety of serologic tests, including immunoblot. The ELISA is performed most frequently, and the antigen used is a whole-cell lysate of the cultured bacteria, usually $B$ hermsii. Patients infected previously with other species of spirochetes may have false-positive reactions in the ELISA and immunofluorescent antibody analysis (IFA). These reactions are in part caused by reactive epitopes on the spirochete's flagellin protein present in other species of bacteria $[62,63]$.

An immunoreactive protein was identified in relapsing fever spirochetes that is absent in Lyme disease spirochetes. The protein, glycerophosphoryl diester phosphodiesterase (GlpQ), was produced with recombinant DNA technology and shown to recognize antibodies made during relapsing fever infections but not with Lyme disease or syphilis [64,65]. Until this antigen is used more widely, serum samples first should be screened by IFA or ELISA with spirochete cells or lysates. An IFA titer of 1:128 to 1:256 or higher is generally considered positive. An ELISA result may be reported with an endpoint titer, but more often an absorptance value, such as 0.85 , is provided with the serum sample tested at one dilution. Positive samples should be tested with immunoblot to determine the pattern of reactivity. A high false-positive titer to a single, nonspecific protein, such as flagellin, can 
occur with the IFA and ELISA. An immunoblot is required to determine if the sample is reactive to other diagnostically specific antigens.

Because relapsing fever spirochetes have a large repertoire of sequentially produced outer surface proteins that vary during infection and when cultivated in vitro, a major antibody response may be made to only a few of many potentially abundant proteins during a human infection. These proteins may not be produced by the spirochete that is used as antigen in the serologic test; this may reduce the reactivity of a sample in the IFA and ELISA falsely. Serologic tests for relapsing fever and other borrelial infections are described in greater detail elsewhere [34]. Importantly, a false-positive Lyme disease serology test result has been observed in TBRF cases [13].

\section{Treatment}

Relapsing fever spirochetes are sensitive to antibiotics, and antimicrobial resistance has not been reported. Before antibiotics, relapsing fever was treated successfully with arsenicals [66]. Treatment options for adults are summarized in Table 3 [2]. The likelihood of producing the Jarisch-Herxheimer reaction for one drug versus another is variable for TBRF and common for LBRF treated with tetracycline [1]. Antibiotics other than those listed in Table 3 have not been investigated for treatment of borreliae and should be avoided. For LBRF, single-dose therapy generally is recommended. A 7-day (or 10-day) course of therapy generally is used for TBRF [2]. There is insufficient information available on the possible efficacy of single-dose therapy for TBRF. Intravenous medication should be administered when oral medication is not tolerated.

Children younger than 8 years and pregnant women should be treated with penicillin or erythromycin [2]. The Jarisch-Herxheimer reaction in children has been reported to be milder than in adults. Monitoring of patients for this reaction after taking the first dose of antibiotic has been recommended for the first 12 hours [13].

\section{Jarisch-Herxheimer reaction}

The Jarisch-Herxheimer reaction, an acute exacerbation of the patient's symptoms, may occur on initial treatment of relapsing fever with an effective antibiotic. It has been reported in 54\% of TBRF cases [13]. In an epidemiologic study that included 33 TBRF patients who had the Jarisch-Herxheimer reaction, age, sex, thrombocytopenia, proteinuria, > 5\% band forms in a differential white blood cell count, and choice of antibiotic were not associated with the reaction. Patients who did not have microhematuria were at an increased risk, however [13]. The pathophysiology of the Jarisch-Herxheimer reaction has been studied best in LBRF. During this reaction the spirochetes disappear rapidly from the circulation, there is massive cytokine release, and treatment with penicillin has been shown to alter the morphology of the dividing spirochetes rapidly, making them susceptible to phagocytosis [67].

Symptoms often include hypotension, tachycardia, chills, rigors, diaphoresis, and marked elevation of body temperature. The reaction typically begins within 1 to 4 hours of the first dose of antibiotic, and the symptoms may be severe. Patients with this reaction have been known to say that they felt as if they were going to die [13]. When possible, patients with LBRF who have the Jarisch-Herxheimer reaction should be transferred to an intensive care unit for close monitoring of fluid balance, measurements of arterial and central venous pressure, and myocardial function [1,2]. Death has been reported as a complication of the reaction, most often secondary to cardiovascular collapse [1]. Patients with TBRF also should be monitored closely. Death from the Jarisch-Herxheimer reaction from TBRF 
acquired in North America has not been reported despite the severity of this reaction, but an opiod partial agonist, meptazinol, has reduced the severity of the symptoms [67].

\section{Unusual and illustrative case report}

During May 2007 a 59-year-old healthy woman from Spokane, Washington was admitted from the hematologist's office. She had been hospitalized several weeks previously for what appeared to be a viral-induced thrombocytopenia (platelets $19,000 / \mathrm{mm}^{3}$, white blood cell count $4,500 / \mathrm{mm}^{3}$, hemoglobin $12.6 \mathrm{~g} / \mathrm{dL}$ ), bone marrow consistent with idiopathic thrombocytopenic purpura, and headache with negative MRI/magnetic resonance angiography and no fever or rash. She had been treated with prednisone, and the platelet count rose to her pre-illness baseline of $245,000 / \mathrm{mm}^{3}$. At her hematology visit 2 weeks later, her temperature was $38.9^{\circ} \mathrm{C}$; she had intense thirst, was unable to ambulate because of muscle pain and mild confusion, and had pancytopenia (white count $1,300 / \mathrm{mm}^{3}$, hemoglobin $8.9 \mathrm{~g} / \mathrm{dL}$, and platelet count of $11,000 / \mathrm{mm}^{3}$ ). Besides mild hypertransaminasemia (alkaline phosphatase $178 \mathrm{U} / \mathrm{L}$, aspartate aminotransferase $128 \mathrm{U} / \mathrm{L}$, alanine aminotransferase $156 \mathrm{U} / \mathrm{L}$ ), and an elevated aldolase level (45.6 U/L), other laboratory values were normal.

She reported no history of camping, sleeping in rustic cabins, or tick exposure. She did comment about recent problems with increases in the chipmunk population in her upscale forested neighborhood and had been clearing knapweed near her home. The patient had traveled to the Galápagos Islands 3 months before her illness, but no one else on that trip had become ill. She had also traveled to Africa 3 years before but had been healthy until now. Another member of her household had had a brief febrile illness at approximately the same time of her original hospitalization but had no sequelae. Her neighbor was hospitalized with fever and a severe respiratory illness requiring mechanical ventilation and antibiotics shortly after arriving in Nevada from Spokane, Washington, but no infecting organism was found, and relapsing fever had not been considered in that case.

Her physical examination was normal except for temperature of $38.9^{\circ} \mathrm{C}$, mild confusion, and mild splenomegaly. A number of diagnostic tests, including peripheral smear, was performed (Badger M. Tick talk: Unusually severe case of tick-borne relapsing fever: Case report and review of the literature. Wilderness and Env Med J, In press) (Fig. 3). The smear contained an extremely high number of spirochetes, as did the bone marrow, which had been examined immediately before admission. Further review from her previous admission found no spirochetes or evidence of malaria parasites. The patient was started on doxycycline and ceftriaxone and did well (no Jarisch-Herxheimer reaction). Admission blood cultures and serology for Rocky Mountain Spotted Fever, ehrlichia, cytomegalovirus, Epstein-Barr virus, Parvovirus, and HIV were all negative. Enzyme immunoassay (EIA) and Western blot from serology samples submitted to the Centers for Disease Control and Prevention Division of Vector-borne Infectious Diseases were positive for $B$ hermsii.

Seventy-six hours after initial antibiotic therapy, the patient had acute hypoxemic respiratory distress with pulmonary edema. Echocardiogram showed an ejection fraction (EF) of less than $20 \%$ and moderate tricuspid regurgitation with a pulmonary artery pressure of $59 \mathrm{~mm}$ $\mathrm{Hg}$. There were no EKG or enzyme changes to suggest infarct or myocarditis. She remained slightly hypertensive (140/90 $\mathrm{mm} \mathrm{Hg}$ ). Despite a rapid return of ejection fraction to 35\%, she had worsening interstitial pulmonary edema, and ARDS was diagnosed by pulmonary and cardiology consultants. Arterial blood gases on $100 \% \mathrm{FIO}_{2}$ demonstrated a pH of 7.49, $\mathrm{PaO}_{2}$ of $57 \mathrm{~mm}$. She required mechanical ventilation with positive end expiratory pressure to correct hypoxemia and compliance. Mechanical ventilation was discontinued after 4 days, and she was rapidly weaned off oxygen. Other complications during hospitalization included 
mild disseminated intravascular coagulation, recurrent pancytopenia, hyponatremia with mental status changes, and liver function abnormalities despite normal blood pressure. Repeated smears for species of Borrelia were negative. Ceftriaxone was discontinued after 14 days, and she was discharged home on doxycycline (21 days of treatment total). Unilateral neurosensory hearing loss was her only sequelae. This case is remarkable for the very substantial quantity of spirochetes observed on the peripheral smear as well as the prolonged and complicated hospitalization.

\section{Prevention}

Prevention of TBRF includes avoiding rodent and tick-infested dwellings and infested natural sites, such as animal burrows or caves. Rodent proofing of homes and vacation cabins and reducing rodent habitat around homes may be performed with the consultation of local health department environmental health specialists and pest removal services. Chemical treatment of rodent-infested areas is available and should be administered by pest control specialists. Contact with ticks and potential animal hosts should occur only while wearing gloves, because TBRF has been contracted after contaminating skin with the blood of an infected animal [36]. Wearing clothing that protects skin (eg, long pants and longsleeved shirts) and applying insect repellents to exposed skin and clothing (eg, permethrin) are methods of prevention for diseases transmitted by hard ticks but are of unclear benefit in preventing TBRF, because persons often are bitten while asleep. Protection during sleeping in a potentially infested dwelling may be provided best by use of topical repellents. Prevention of LBRF occurs through control of lice by promoting personal hygiene and systematic delousing, for example with permethrin [2]. Control of epidemics may also involve widespread antibiotic use. Reporting of TBRF to local health departments is encouraged for cases diagnosed in states where TBRF is reportable (ie, Arizona, California, Colorado, Idaho, New Mexico, Montana, Nevada, Oregon, Texas, Utah, Washington, and Wyoming).

Surveillance is information for action. In the case of TBRF, that action may include prevention and education of the public and physicians about the epidemiology and clinical presentation of the disease. Accurate surveillance data are vital to furthering understanding of this tick-borne disease.

\section{References}

1. Goubau PF. Relapsing fevers. A review. Ann Soc Belg Med Trop. 1984; 64:335-364. [PubMed: 6397148]

2. Dennis, DT.; Hayes, EB. Relapsing fever. In: Braunwald, E.; Hauser, SL.; Fauci, AS., editors. Harrison's principles of internal medicine. 16th edition. New York: McGraw-Hill; 2005. p. 991-995.

3. Southern PM, Sanford JP. Relapsing fever: a clinical and microbiological review. Medicine. 1969; 48:129-149.

4. Washington State Department of Health. Morbidity and mortality summary. Seattle (Washington): Washington State Department of Health; 1993. Relapsing fever; p. 77-78.

5. Moursund, WH. Historical introduction to the symposium on relapsing fever. In: Moulton, FR., editor. A symposium on relapsing fever in the Americas. Washington, DC: American Association for the Advancement of Science; 1942. p. 1-6.

6. Wynns, HL. The epidemiology of relapsing fever. In: Moulton, FR., editor. A symposium on relapsing fever in the Americas. Washington, DC: American Association for the Advancement of Science; 1942. p. 100-105.

7. Meador CN. Five cases of relapsing fever originating in Colorado, with positive blood findings in two. Colorado Med. 1915; 12:365-368. 
8. Edell TA, Emerson JK, Maupin GO, et al. Tick-borne relapsing fever in Colorado: Historical review and report of cases. JAMA. 1979; 241:2279-2281. [PubMed: 374757]

9. Davis GE. Ornithodoros hermsi and relapsing fever in Oregon. Public Health Rep. 1941; 56:20102012.

10. Davis GE. Ornithodoros turicata: The possible vector of relapsing fever in southwestern Kansas. Public Health Rep. 1936; 51:1719.

11. Davis GE. Ticks and relapsing fever in the United States. Public Health Rep. 1940; 55:2347-2351.

12. Palmer JH, Crawford DJM, et al. Relapsing fever in North America, with report of an outbreak in British Columbia. Can Med Assoc J. 1933; 28:643-650. [PubMed: 20319139]

13. Dworkin MS, Anderson DE Jr, Schwan TG, et al. Tick-borne relapsing fever in the Northwestern United States and Southwestern Canada. Clin Infect Dis. 1998; 26:122-131. [PubMed: 9455520]

14. Thompson RS, Burgdorfer W, Russell R, et al. Outbreak of tick-borne relapsing fever in Spokane County, Washington. JAMA. 1969; 210:1045-1050. [PubMed: 5394422]

15. Boyer KM, Munford RS, Maupin GO, et al. Tick-borne relapsing fever: an interstate outbreak originating at Grand Canyon National Park. Am J Epidemiol. 1977; 105:469-479. [PubMed: 871120]

16. Centers for Disease Control and Prevention. Common source outbreak of relapsing feverCalifornia. MMWR Morb Mortal Wkly Rep. 1990; 39:579-586. [PubMed: 2117241]

17. Centers for Disease Control and Prevention. Outbreak of relapsing fever - Grand Canyon National Park, Arizona, 1990. MMWR Morb Mortal Wkly Rep. 1991; 40:296-297. [PubMed: 1902280]

18. Paul WS, Maupin G, Scott-Wright AO, et al. Outbreak of Tick-borne relapsing fever at the North Rim of the Grand Canyon: evidence for effectiveness of preventive measures. Am J Trop Med Hyg. 2002; 66:71-75. [PubMed: 12135272]

19. Rawlings JA. An overview of tick-borne relapsing fever with emphasis on outbreaks in Texas. Tex Med. 1995; 91:56-59. [PubMed: 7778052]

20. Trevejo RT, Schriefer ME, Gage KL, et al. An interstate outbreak of tick-borne relapsing fever among vacationers at a Rocky Mountain cabin. Am J Trop Med Hyg. 1998; 58:743-747. [PubMed: 9660457]

21. Centers for Disease Control and Prevention. Tickborne relapsing fever outbreak after a family gathering-New Mexico, August 2002. MMWR Morb Mortal Wkly Rep. 2003; 52:809-812. [PubMed: 12944877]

22. Schwan TG, Policastro PF, Miller Z, et al. Tick-borne relapsing fever caused by Borrelia hermsii, Montana. Emerg Infect Dis. 2003; 9:1151-1154. [PubMed: 14519254]

23. Cleary M, Theis J. Identification of a novel strain of Borrelia hermsii in a previously undescribed northern California focus. Am J Trop Med Hyg. 1999; 60:883-887. [PubMed: 10403314]

24. Dworkin MS, Shoemaker PC, Fritz CL, et al. The epidemiology of tick-borne relapsing fever in the United States. Am J Trop Med Hyg. 2002; 66:753-758. [PubMed: 12224586]

25. Banerjee SN, Banerjee M, Fernando K, et al. Tick-borne relapsing fever in British Columbia, Canada: First isolation of Borrelia hermsii. J Clin Microbiol. 1998; 36:3505-3508. [PubMed: 9817862]

26. Closson HO. Relapsing fever. J Kans Med Soc. 1934; 35:53-54.

27. Fisher, WM. Present distribution of relapsing fever in Oklahoma. In: Moulton, FR., editor. A Symposium on relapsing fever in the Americas. Washington, DC: American Association for the Advancement of Science; 1942. p. 15-19.

28. Linnemann CC Jr, Barber LC, Dine MS, et al. Tick-borne relapsing fever in the Eastern United States. Am J Dis Child. 1978; 132:40-42. [PubMed: 623062]

29. Scoles GA, Papero M, Beati L, et al. Arelapsing fever group spirochete transmitted by Ixodes scapularis ticks. Vector Borne Zoonotic Dis. 2001; 1:21-34. [PubMed: 12653133]

30. Flanigan TP, Schwan TG, Armstrong C, et al. Relapsing fever in the US Virgin Islands: A previously unrecognized focus of infection. J Infect Dis. 1991; 163:1391-1392. [PubMed: 2037807]

31. Felsenfeld, O. Borrelia: strains, vectors, human and animal borreliosis. St Louis (MO): Warren H Green, Inc.; 1971. 
32. Stoenner HG, Dodd T, Larsen C. Antigenic variation of Borrelia hermsii. J Exp Med. 1982; 156:1297-1311. [PubMed: 7130900]

33. Barbour A. Antigenic variation of a relapsing fever Borrelia species. Annu Rev Microbiol. 1990; 44:155-171. [PubMed: 2252381]

34. Schwan, TG.; Burgdorfer, W.; Rosa, PA. Borrelia. In: Murray, PR.; Baron, EJ.; Pfaller, MA., editors. Manual of clinical microbiology. 7th edition. Washington, DC: American Society for Microbiology; 1999. p. 746-758.

35. Brumpt E, Brumpt LC. Identite du spirochete des fievre recurrentes a tiques des plateaux mexicins et du Spriochaeta turicatae, agent de la fievre recurrente sporadique de Etats-Unis. Ann Parasitol Hum Comp. 1939; 18:287-312.

36. Beck, MD. Present distribution of relapsing fever in California. In: Moulton, FR., editor. A Symposium on relapsing fever in the Americas. Washington, DC: American Association for the Advancement of Science; 1942. p. 20-25.

37. Carlisle RF. Two cases of relapsing fever; with notes on the occurrence of this disease throughout the world at the present day. J Infect Dis. 1906; 3:233-265.

38. Favorova LA, Chernyshova TF, Mikhailov AK. Results of inoculation of volunteers with Borrelia passaged through lice. Med Parazitol (Mosk). 1971; 40:443-446. [in Russian]. [PubMed: 5134381]

39. Lopez-Cortes L, Lozano De Leon F, Gomez-Mateos JM, et al. Tick-borne relapsing fever in intravenous drug abusers. J Infect Dis. 1989; 159:804. [PubMed: 2926174]

40. Cooley RA, Kohls GM. The Agarasidae of North America, Central America, and Cuba. Monograph No. 1. American Midland Naturalist. 1944:1-152.

41. Davis, GE. The endemic relapsing fevers. In: Hull, TG., editor. Diseases transmitted from animals to man. Springfield (IL): Charles C Thomas; 1955. p. 552-565.

42. Horton JM, Blaser MJ. The spectrum of relapsing fever in the rocky mountains. Arch Intern Med. 1985; 145:871-875. [PubMed: 3994463]

43. Schwan TG, Hinnebusch BJ. Bloodstream-versus tick-associated variants of a relapsing fever bacterium. Science. 1998; 280:1938-1940. [PubMed: 9632392]

44. Schwan, TG.; Winkler, DW. Ticks parasitizing humans and California gulls at Mono Lake, California. In: Griffths, DA.; Bowman, CE., editors. Acarology VI. Chichester (UK): Ellis Horwood LTD; 1984. p. 1193-1199.

45. Francis E. Longevity of the tick Ornithodoros turicata and of Spirochaeta recurrentis with this tick. Public Health Rep. 1938; 53:2220-2241.

46. Beck AF, Holscher KH, Butler JF. Life cycle of Ornithodoros turicata americanus (Acari: Argasidae) in the laboratory. J Med Entomol. 1986; 23:313-319. [PubMed: 3735335]

47. Breitschwerdt EB, Nicholson WL, Kiehl AR, et al. Natural infections with Borrelia spirochetes in two dogs from Florida. J Clin Microbiol. 1994; 32:352-357. [PubMed: 8150943]

48. Schwan TG, Raffel SJ, Schrumpf ME, et al. Phylogenetic analysis of the spirochetes Borrelia parkeri and Borrelia turicatae and the potential for tick-borne relapsing fever in Florida. J Clin Microbiol. 2005; 43:3851-3859. [PubMed: 16081922]

49. Davis GE. Ornithodoros parkeri: Distribution and host data: Spontaneous infection with relapsing fever spirochetes. Public Health Rep. 1939; 54:1345-1350.

50. Hinnebusch BJ, Barbour AG, Restrepo BI, et al. Population structure of the relapsing fever spirochete Borrelia hermsii as indicated by polymorphism of two multigene families that encode immunogenic outer surface proteins. Infect Immun. 1998; 66:432-440. [PubMed: 9453591]

51. Bryceson AD, Parry EH, Perine PL, et al. Louse-borne relapsing fever: A clinical and laboratory study of 62 cases in Ethiopia and a reconsideration of the literature. QJM. 1970; 39:129-170. [PubMed: 4913454]

52. Fuchs PC, Oyama AA. Neonatal relapsing fever due to transplacental transmission of Borrelia. JAMA. 1969; 208:690-692. [PubMed: 5818572]

53. Yagupsky P, Moses S. Neonatal Borrelia species infection (relapsing fever). Am J Dis Child. 1985; 139:74-76. [PubMed: 3969988] 
54. Dworkin MS, Schwan TG, Anderson DE Jr. Tick-borne relapsing fever in North America. Med Clin North Am. 2002; 86(2):417-433. [PubMed: 11982310]

55. Centers for Disease Control and Prevention. Acute respiratory distress syndrome in persons with tickborne relapsing fever-three states, 2004-2005. MMWR Morb Mortal Wkly Rep. 2007; 56:1073-1076. [PubMed: 17947965]

56. Burgdorfer, W. The diagnosis of relapsing fevers. In: Johnson, RC., editor. The biology of parasitic spirochetes. New York: Academic Press; 1976. p. 225-234.

57. Chatel G, Gulletta M, Matteelli A, et al. Diagnosis of tick-borne relapsing fever by the quantitative buffy coat fluorescence method. Am J Trop Med Hyg. 1999; 60:738-739. [PubMed: 10344644]

58. van Dam AP, van Gool T, Wetsteyn JC, et al. Tick-borne relapsing fever imported from West Africa: diagnosis by quantitative buffy coat analysis and in vitro culture of Borrelia crocidurae. J Clin Microbiol. 1999; 37:2027-2030. [PubMed: 10325370]

59. Kelly R. Cultivation of Borrelia hermsi. Science. 1971; 173:443-444. [PubMed: 5557322]

60. Schwan TG, Gage KL, Karsten RH, et al. Identification of the tick-borne relapsing fever spirochete Borrelia hermsii by using a species-specific monoclonal antibody. J Clin Microbiol. 1992; 30:790_ 795. [PubMed: 1572965]

61. Fukunaga M, Okada K, Nakao M. Phylogenetic analysis of Borrelia species based on flagellin gene sequences and its application for molecular typing of Lyme disease borreliae. Int J Syst Bacteriol. 1996; 46:898-905. [PubMed: 8863416]

62. Magnarelli LA, Anderson JF, Johnson RC. Cross reactivity in serological tests for Lyme disease and other spirochetal infections. J Infect Dis. 1987; 156:183-187. [PubMed: 3298452]

63. Magnarelli LA, Meegan JM, Anderson JF, et al. Comparison of an indirect fluorescentantibody test with an enzyme-linked immunosorbent assay for serological studies of Lyme disease. J Clin Microbiol. 1984; 20:181-184. [PubMed: 6386843]

64. Porcella SF, Raffel SJ, Schrumpf ME, et al. Serodiagnosis of louse-borne relapsing fever with glycerophosphodiester phosphodiesterase (GlpQ) from Borrelia recurrentis. J Clin Microbiol. 2000; 38:3561-3571. [PubMed: 11015364]

65. Schwan TB, Schrumpf ME, Hinnebusch BJ, et al. GlpQ: an antigen for serological discrimination between relapsing fever and Lyme borreliosis. J Clin Microbiol. 1996; 34:2483-2492. [PubMed: 8880505]

66. Hemingway MW, Hemingway RW, Arneson VK. Relapsing fever. Northwest Med. 1940; 39:362364.

67. Griffin GE. Cytokines involved in human septic shock-the model of the Jarisch-Herxheimer reaction. J Antimicrob Chemother. 1998; 41(Suppl A):25-29. [PubMed: 9511083] 


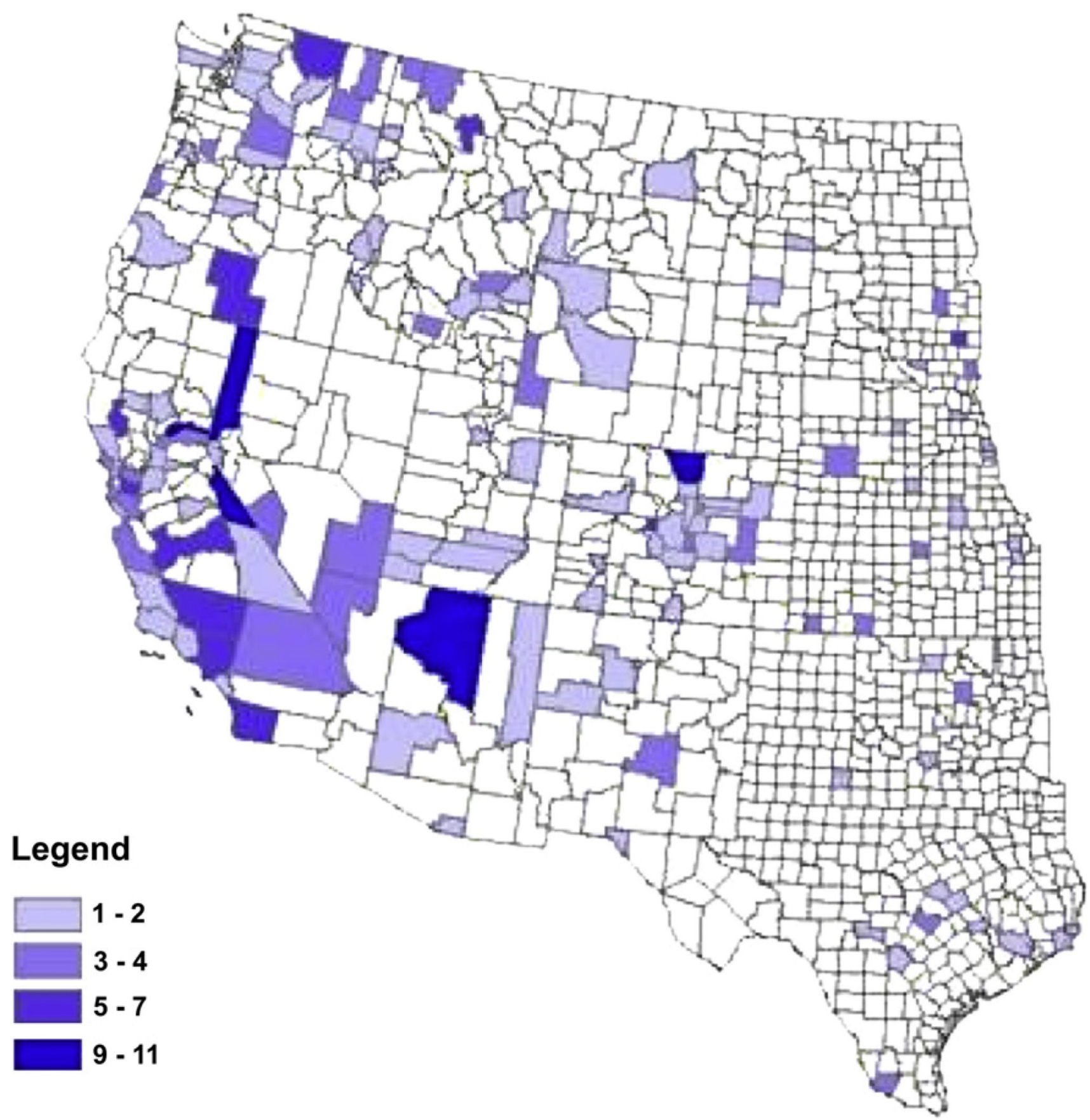

Fig. 1.

Reported cases of tick-borne relapsing fever by county, United States, 1990 to 2002 (From Centers for Disease Control and Prevention. Tick borne relapsing fever trends. Available at: http://www.cdc.gov/ncidod/dvbid/RelapsingFever/TBRF_DiseaseTrends.html. Accessed December 12, 2007.) 

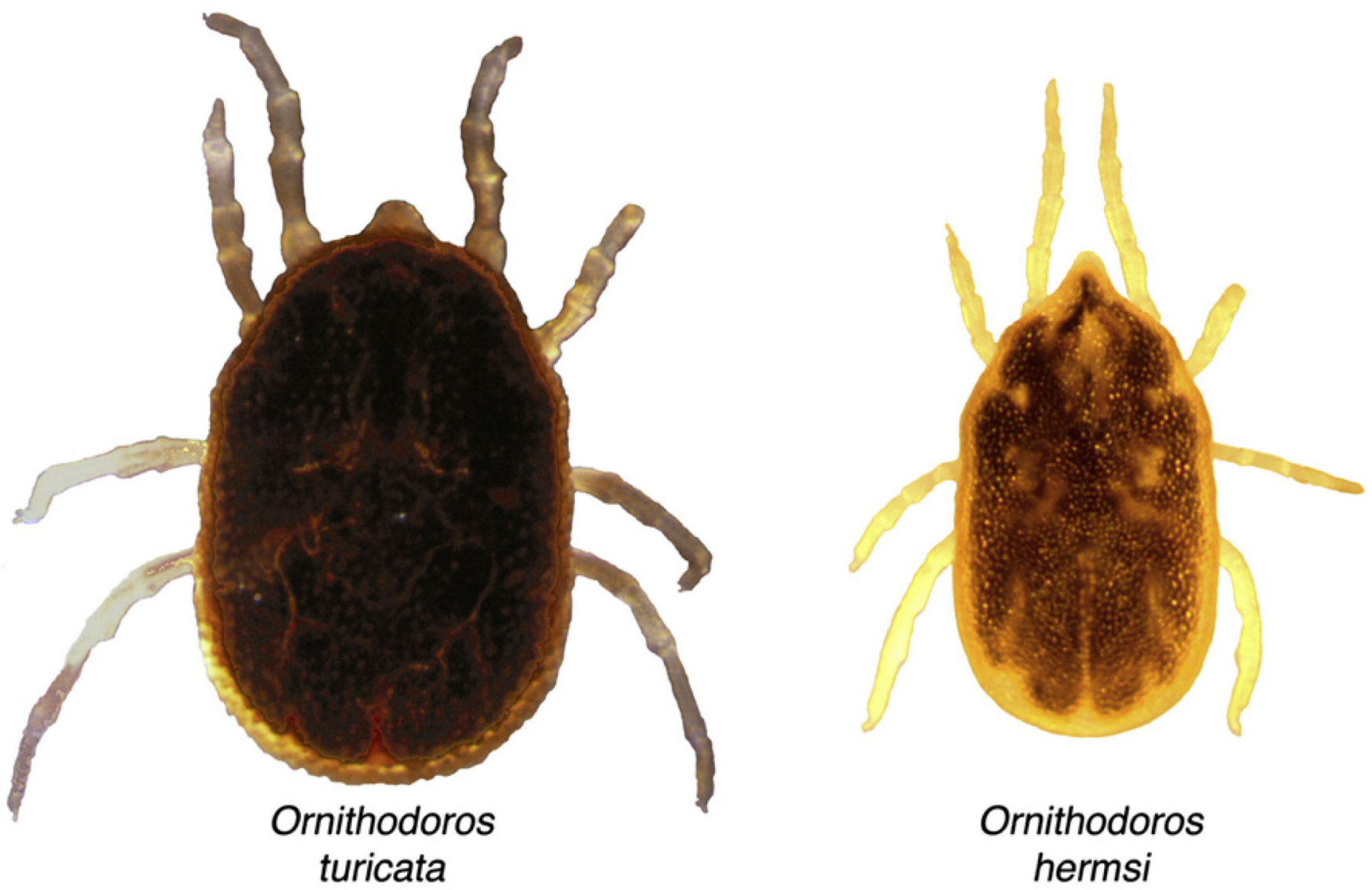

\section{Ornithodoros hermsi}

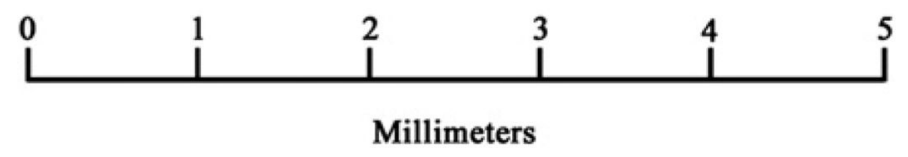

Fig. 2.

Ornithodoros hermsi (right) and Ornithodoros turicata (left). 


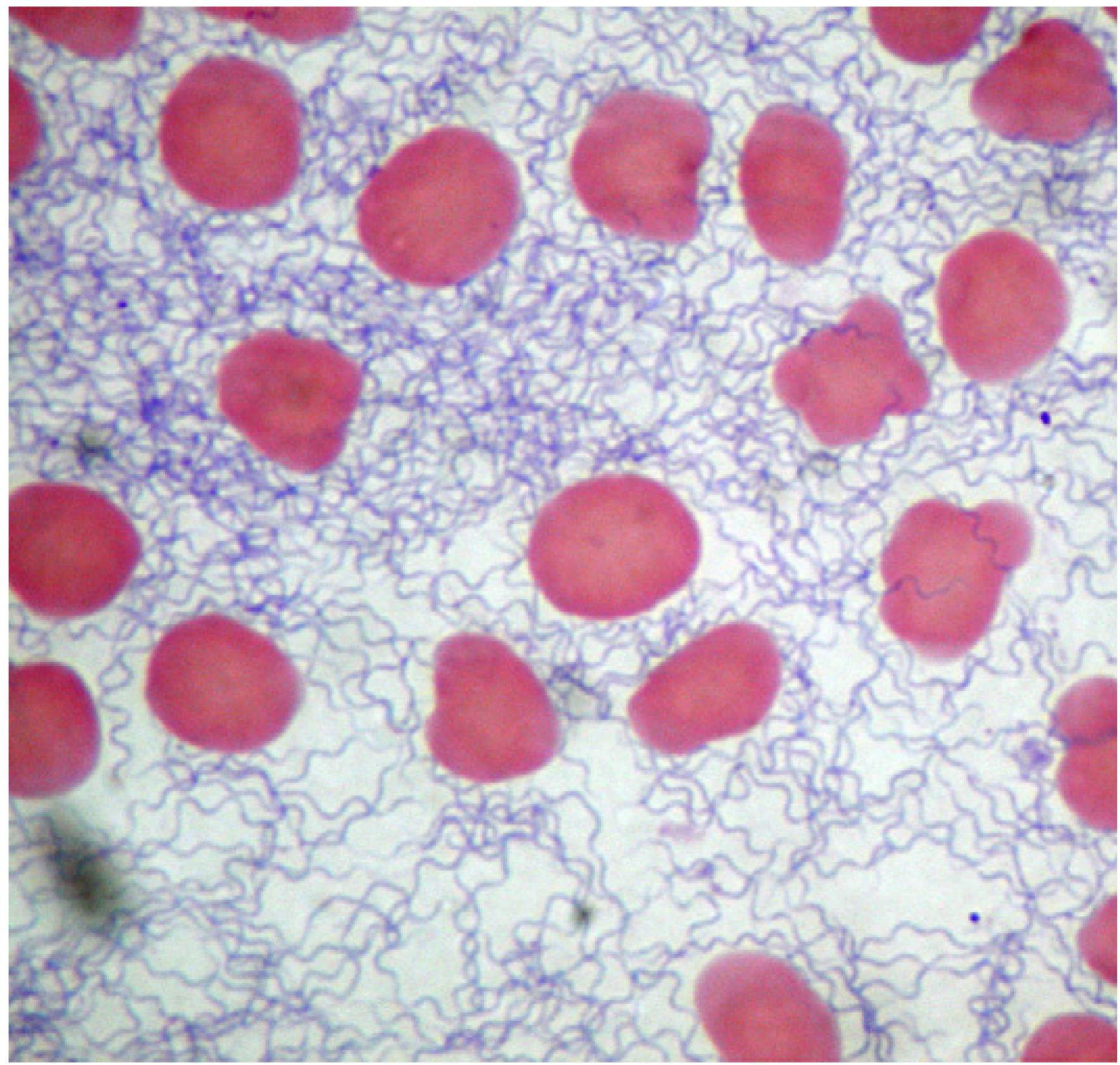

Fig. 3.

Borrelia hermsii in a stained peripheral blood smear from an infected woman. (From Badger M. Tick talk: Unusually severe case of tick-borne relapsing fever: Case report and review of the literature. Wilderness Env Med J 2008, in press; with permission.) 


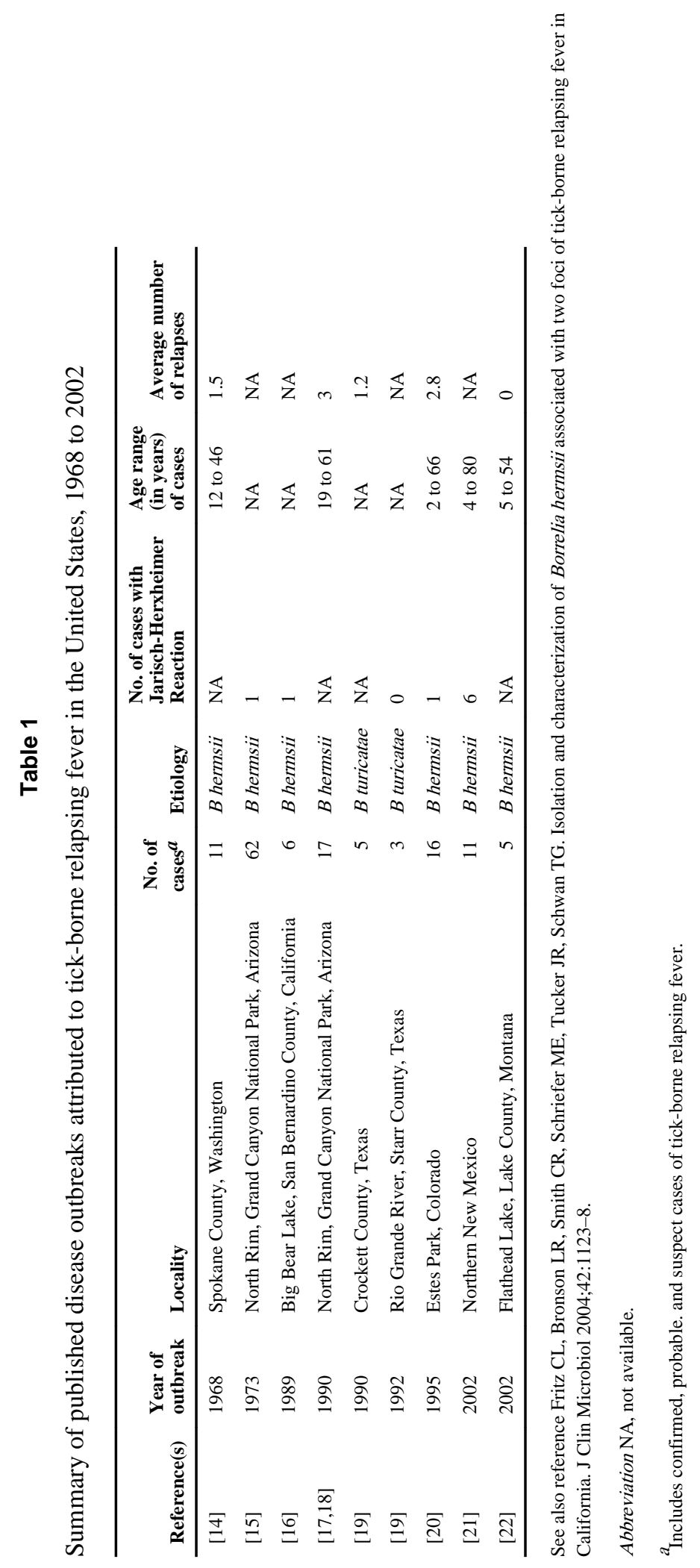

Infect Dis Clin North Am. Author manuscript; available in PMC 2013 July 29. 


\section{Table 2}

Manifestations of tick-borne relapsing fever acquired in the northwestern United States and southwestern British Columbia

\begin{tabular}{llll}
\hline Sign or symptom & $\%$ & Sign or symptom & $\%$ \\
\hline Headache & 94 & Photophobia & 25 \\
Myalgia & 92 & Neck pain & 24 \\
Chills & 88 & Rash & 18 \\
Nausea & 76 & Dysuria & 13 \\
Arthralgia & 73 & Jaundice & 10 \\
Vomiting & 71 & Hepatomegaly & 10 \\
Abdominal pain & 44 & Splenomegaly & 6 \\
Confusion & 38 & Conjunctival injection & 5 \\
Dry cough & 27 & Eschar & 2 \\
Eye pain & 26 & Meningitis & 2 \\
Diarrhea & 25 & Nuchal rigidity & 2 \\
Dizziness & 25 & & \\
\hline
\end{tabular}


Table 3

Treatment options for relapsing fever in adults

\begin{tabular}{lll}
\hline Medication & $\begin{array}{l}\text { Tick-borne relapsing fever } \\
\text { (7-day adult dosage schedule) }\end{array}$ & $\begin{array}{l}\text { Louse-borne relapsing } \\
\text { fever (single adult dose) }\end{array}$ \\
\hline Oral & & \\
Chloramphenicol & $500 \mathrm{mg}$ every 6 hours & $500 \mathrm{mg}$ \\
Doxycycline & $100 \mathrm{mg}$ every 12 hours & $100 \mathrm{mg}$ \\
Erythromycin & $500 \mathrm{mg}$ every 6 hours & $500 \mathrm{mg}$ \\
Tetracycline & $500 \mathrm{mg}$ every 6 hours & $500 \mathrm{mg}$ \\
Parenteral & \\
Chloramphenicol & $500 \mathrm{mg}$ every 6 hours & $500 \mathrm{mg}$ \\
Doxycycline & $100 \mathrm{mg}$ every 12 hours & $100 \mathrm{mg}$ \\
Erythromycin & $500 \mathrm{mg}$ every 6 hours & $500 \mathrm{mg}$ \\
Penicillin G (procaine) & 600,000 IU daily & $600,000 \mathrm{IU}$ \\
Tetracycline & $250 \mathrm{mg}$ every 6 hours & $250 \mathrm{mg}$ \\
\hline
\end{tabular}

a Parenteral medication should be continued until oral medication is tolerated. If oral medication is tolerated at the time of diagnosis, parenteral medication may not be necessary.

Data from Dennis DT, Hayes EB. Relapsing fever. In: Braunwald E, Hauser SL, Fauci AS, Longo DL, Kasper DL, Jameson JL, editors. Harrison's principles of internal medicine. 16 $6^{\text {th }}$ edition. New York: McGraw-Hill; 2005. 